\title{
Efficient inhibition of intraperitoneal human ovarian cancer growth by short hairpin RNA targeting CD44
}

\author{
L. ZOU ${ }^{1}$, T. YI $I^{1}$ X. SONG ${ }^{2}$, S. $\mathrm{LI}^{2}$, Y. $\mathrm{WEI}^{2}$, X. ZHAO ${ }^{1, *}$
}

${ }^{1}$ Department of Obstetrics and Gynecology, Key Laboratory of Obstetric \& Gynecologic and Pediatric Diseases and Birth Defects of Ministry of Education, West China Second Hospital, Sichuan University, Chengdu, 610041, People's Republic of China; ${ }^{2}$ State Key Laboratory of Biotherapy, Sichuan University, Chengdu, 610041, People's Republic of China

${ }^{*}$ Correspondence: xia-zhao@126.com

Received February 1, 2013 / Accepted November 6, 2013

CD44 is one member of a big glycoprotein family involved in adhesion of cells or cells and extracellular matrix (ECM). The heavily glycosylated CD44 has been proved to be a major receptor of hyaluronan and a marker of stem cells in ovarian cancer. Here, using short hairpin (shRNA) against CD44, we demonstrate that knockdown CD44 could inhibit cancer growth efficiently compared with controls. Plasmid targeting CD44 gene (pshCD44) or non-relative control sequences (pshHK) was constructed and delivered to ovarian cancer by biodegradable poly D, L-Lactide-co-glycolide acid nanoparticles (PLGANPs). Nude mice were utilized in an intraperitoneal model of ovarian carcinomatosis to assess antitumor efficacy in vivo. Antitumor efficacy was estimated by changes in tumor weights, proliferation (Ki-67), apoptosis (TUNEL) and angiogenesis (CD31 staining and alginate-encapsulated tumor beads assay) in tumor cells. As results, pshCD44 or pshHK could be effectively transfected into SKOV-3 cells by PLGANPs. Tumor weight in pshCD44/PLGANPs group was suppressed by $45 \%$ and 50\% compared with those in pshHK/PLGANPs and untreated group, respectively $(P s<0.001)$. Inhibition of cell proliferation, induction of apoptosis and reduction of angiogenesis in tumor cells of pshCD44/PLGANPs group also show significant difference compared with those in control groups $(P s<0.05)$, respectively. These results indicate that pshCD44 delivered by PLGANPs might be a potential approach in ovarian cancer therapy, and point towards a mechanism involving the inhibition of angiogenesis, cellular proliferation and the induction of apoptosis.

Key words: CD44, shRNA, ovarian cancer, PLGA nanoparticles

Ovarian cancer cells are characterized by widespread affinity to peritoneal epithelium, which causes tumor cells diffusing freely in peritoneal cavity and leads ovarian cancer to be a dramatically aggressive tumor. Ovarian cancer ranks the fifth in causing cancer-related morbidity in females and the first leading-death cancer in gynecologic oncology [1].

A plenty of researches exploring gene targets are aimed to improve treatment of ovarian cancer. CD44 is an ideal one of these candidates, which belongs to a big transmembrane glycoprotein family widely expressed in ovarian cancer tissues [2] and play mediating ovarian carcinoma cell adhesion to peritoneal mesothelial cells [3]. In addition, CD44 was one major receptor of hyaluronan. Inhibiting interaction of CD44 and hyaluronan showed suppressions of various anti-apoptosis cell survival pathways and tumor growth [4]. Owing to a considerable CD44 isoforms generated by various splicing in tumor growth and metastasis [5], various studies had been done to target various CD44 isoforms in inhibitions of different tumor growth [6-8]. CD44 was also reported as a marker of ovarian cancer stem cells [9]. Small interfering RNA (siRNA) targeting CD44 showed efficient therapy of ovarian cancer [10]. Based on above findings, a recombinant plasmid expressing short hairpin RNA (shRNA), a relative stable and sustainable RNA interfering approach than siRNA [11], targeting CD44 gene (pshCD44) was constructed to estimate the antitumor efficacy in ovarian cancer in current study.

A safe and efficient gene carrier is crucial to gene therapy, which holds a potential promising for therapeutic approach in tumors. Owing to high efficiency of adenovirus delivery system accompanying of safty problems [12], more attentions were oriented on nonviral vectors. Nonviral delivery systems are advantageous due to their low cytotoxicity, low immuno- 
genicity and improved safety profile when compared to that of viral vectors [13-15]. In recent years, poly (d,1-lactide-co-glycolide acid) (PLGA) nanoparticles (PLGANPs) have attracted considerable attention and interest due to their low toxicity, and excellent biodegradability and biocompatibility [16-18]. In addition, PLGANPs have been used in conjunction with short hairpin RNA (shRNA) to both efficiently express and knockdown genes in tumor cells with limited toxicity [19, 20]. Therefore, we chose to silence the expression of CD44 in ovarian tumors using a recombinant plasmid vector based on shRNA encapsulated with PLGANPs.

\section{Materials and methods}

ShRNA plasmid vectors construction. Oligonucleotide sequences CD44 (sense, 5'-TCC CGT ATG ACA CAT ATT GCT TCT TCA AGA CGG AAG CAA TAT GTG TCA TAC TTT TTT G -3'; antisense, 5'-AGC TCA AAA AAG TAT GAC ACA TAT TGC TTC CGT CTG AAG AAG CAA TAT GTG TCA TAC - $3^{\prime}$ ) was designed according to the design principle and an identified research [21]. HK (sense, 5'-GAT CCG ACT TCA TAA GGC GCA TGC TTC AAG ACG GCA TGC GCC TTA TGA AGT CTT TTT TGT CGA CA; antisense, 3'-GCT GAA GTA TTC CGC GTA CGA AGT TCT GCC GTA CGC GGA ATA CTT CAG AAA AAA CAG CTG TTC GA-5') was designed in principle of no homology to any human gene. pshCD44 was cloned into pGensile-2 plasmid, which holding kanamycin resistance gene. pGensile-2 was linearized with Eco31I, ligated with annealed olignucleotide templates CD44 into a plasmid vector using T4 DNA ligase, respectively. The resultant recombinant plasmid was digested to ensure its correctness, and the identity of CD44 genes cloned into pGenesile- 2 was finally confirmed by DNA sequencing. pshHK was constructed as similar methods described above, used as one of control groups. Colonies of pshCD44 or pshHK were cultured in Luria-Bertani broth containing $100 \mu \mathrm{g} / \mathrm{ml}$ kanamycin. Large plasmid DNA was purified using an EndoFree Plasmid Giga kit (Qiagen, Chatsworth, CA) and dissolved in sterile endotoxin-free water at a concentration of $1 \mathrm{mg} / \mathrm{ml}$, stored at $-20^{\circ} \mathrm{C}$ for future use.

PLGANPs preparation and characteristics. PLGANPs encapsulating pshCD44 or pshHK were prepared similarly as previously described $[19,22]$. Before large quantities of PLGANPs loaded with pshCD44 or pshHK were performed, all procedure variables had been optimized and quantized. In brief, pshCD44 or pshHK was firstly condensed via incubation with equivalent ploy-L-lysine (PLL with MW $25 \mathrm{kDa}$, Sigma) at $37^{\circ} \mathrm{C}$ shaking table for 30 minutes. The complex of pshCD44 or pshHK and PLL were added drop by drop into chloroformacetone $(9: 1, \mathrm{v} / \mathrm{v})$ mixture containing PLGA (LA: GA = 75: 25, MW $50 \mathrm{kDa}$, Department of Medical Polymers Shan Dong Institute, China), and then was emulsified by probe sonication in an ice bath under $20 \mathrm{~W}$ voltage for 20 seconds. The resulting primary emulsions were mixed with TE buffer containing polyvinyl alcohol (PVA, Sigma, USA) and further emulsified under
$40 \mathrm{~W}$ voltage for 20 seconds in an ice bath, thereby forming the $\mathrm{W} / \mathrm{O} / \mathrm{W}$ double emulsion. The organic solvent in the double emulsion was removed by evaporation at $37^{\circ} \mathrm{C}$ on a rotary evaporation instrument to achieve pshCD44 or pshHK loaded in PLGANPs (pshCD44/PLGANPs or pshHK/PLGANPs) suspension. Finally, the suspension was centrifuged to remove the remained PVA in the supernatants and then re-diffused in sterile distilled water. After repetitive centrifugations and re three times re-diffusions, pshCD44/PLGANPs or pshHK/PLGANPs were stored at $4^{\circ} \mathrm{C}$ for further study within 2 weeks.

The mean diameter (MD) of each pshDNA/PLGANPs was evaluated by laser scattering particle size analyzer, Zetsizer Nano ZS90 (Malvern Instruments Ltd., Malvern, UK), in triplicate. Zeta potential, MD and polydispersity index (PDI) of nanoparticles were recorded. The entrapment efficiency (EE) and gene-loading rate (GLR) of pshDNAs could be calculated according to the quantity of entrapped pshDNA, PLGA polymer and free pshDNA in supernatants [22]. The free pshDNA content in supernatants obtained from pshDNA/PLGANPs suspension after ultracentrifrugation (Optima Optima ${ }^{\mathrm{TM}} \mathrm{L}$ 80 XP Ultracentrifuge, Beckman Coulter, USA) at $10^{\circ} \mathrm{C}$ and the speed of $15,000 \mathrm{rpm}$ for 30 minutes, were quantitated using UV-spectroscopy (RF-5301PC, Japan). After stained by Hochest 33258 staining solution (Sigma), the absorbance value monitoring at $455 \mathrm{~nm}$ was used to count the amount of pshDNA unencapsulated. All experiments were repeated triply.

Cell culture and transfection conditions. The human ovarian serous cystadenocarcinoma cells line SKOV3 was obtained from American Type Culture Collection (ATCC, Manassas, VA) and incubated in a humidified atmosphere containing $5 \% \mathrm{CO}_{2}$ at $37^{\circ} \mathrm{C}$. Cells were cultured in Dulbecco's modified Eagle's medium (DMEM) supplemented with $10 \%$ fetal bovine serum (FBS), $2 \mathrm{mM} \mathrm{L}$-glutamine, $100 \mathrm{U} / \mathrm{ml}$ penicillin $\mathrm{G}$ and $100 \mu \mathrm{g} / \mathrm{ml}$ streptomycin, and passaged on reaching $70 \%-80 \%$ confluence at a split ratio of $1: 3$.

SKOV 3 cell $\left(2 \times 10^{5}\right)$ were plated in 6-well plates and cultured for 24 hours to $30 \%$ - $40 \%$ confluence. Five microgram (5 $\mu \mathrm{g}$ ) of pshCD44 or pshHK was entrapped in each $100 \mu \mathrm{L}$ PLGANPs as described before and then diluted in $1 \mathrm{ml}$ DMEM medium without antibiotics and serum. After incubating 6 hours, the medium was changed to $2 \mathrm{ml}$ DEME with FBS and antibiotics. Then, RNA and protein samples of cells were collected for further analyses after 60-72 hours of incubation.

Reverse transcription polymerase chain reaction (RTPCR). Total RNAs were isolated from cells or tumor tissues using TRIzol reagent (Invitrogen, Grand Island, NY). The primers of $\mathrm{CD} 44$ were designed based on cDNA sequence with upstream primers 5'-GCT CAT ACC AGC CAT CCA AT-3' and downstream primers 5'-GAG GTC CTG TCC TGT CCA AA-3', respectively. The predicted RT-PCR products and the best annealing temperature of $\mathrm{CD} 44$ was $211 \mathrm{bp}$ and $55^{\circ} \mathrm{C}$, respectively. Five microliters $(5 \mu \mathrm{l})$ of each RT-PCR product was electrophoresed on $1 \%$ agarose gel. The housekeeping gene GAPDH was used as an internal control. 
Western blot analysis. Cells or tumor tissues were lysed using RIPA lysis buffer $(50 \mathrm{mM}$ This-HCL, $0.25 \%$ sodium deoxycholate, $150 \mathrm{mM} \mathrm{NaCl}, 1 \% \mathrm{NP}-40,1 \mathrm{mM} \mathrm{NaF}$, and $1 \mathrm{mM}$ $\mathrm{Na}_{3} \mathrm{~V}_{4}$ ) containing $1 \mathrm{mM}$ cocktail (protein inhibitor, Sigma, St. Louis, MO) and centrifuged at $12,000 \mathrm{rpm}, 4^{\circ} \mathrm{C}$, for 30 minutes. The total protein concentrations of supernatant were determined using Bio-Rad protein assay (Hercules, Calif). Equal amounts of proteins were separated on $10 \%$ SDS-PAGE gels and transferred onto polyvinylidene difluoride membranes (PVDF, Bio-Rad, CA). After being blocked with 5\% nonfat milk 2 hours, membranes were immunoblotted with mouse monoclonal antibody against CD44 (1:500 dilution, mAb, Santa Cruz Biotechnology, Santa Cruz, CA) over night at $4^{\circ} \mathrm{C}$. Followed by incubating goat anti-mouse secondary (1: 3,000 , ZSGB-BIO, Beijing, China) for 1 hour at $37^{\circ} \mathrm{C}$. Equal loading was normalized by GAPDH (1: 1,000 dilution, ZSGB-BIO, Beijing, China) and all bands were observed with an enhanced chemiluminescence detection system (Pierce Biotech Inc., Rockford, IL, USA).

Tumor xenograft model and treatment. All animal experiments were approved and supervised by the Institutional Animal Care and Use Committee of Sichuan University and were in accordance with all regulations and guidelines of China. Female athymic BALB/c nude mice, 6- 8 week old, housed in pathogen-free conditions and fed sterile chow, were used to establish the intraperitoneal carcinomatosis model modified from previous study [23]. Briefly, SKOV3 cells suspension $\left(5 \times 10^{6}\right.$ cells in $100 \mu \mathrm{l}$ of DMEM medium without serum and antibiotics) was injected s.c. into the right flank of each mouse. When the diameter was about $1 \mathrm{~cm}$, tumors were collected and minced with 6 layers of stainless trap valves, a diameter of aperture no more than $1 \mathrm{~mm}$. Sufficient DMEM medium was added and adjust to a final volume of $7.5 \mathrm{ml}, 15$ nude mice were inoculated intraperitoneal (i.p.) with $0.5 \mathrm{ml}$ of mixture for each in the right lower quadrant with a 14-gauge needle, respectively. Mice were distributed randomly into three groups (five per group): (a) untreated group, $100 \mu \mathrm{l} 0.9 \% \mathrm{NaCl}$; (b) pshHK/PLGANPs group, $5 \mu \mathrm{g}$ pshHK/100 $\mu$ l PLGANPs; and (c) pshCD44/PLGANPs group: $5 \mu \mathrm{g}$ pshCD44/100 $\mu \mathrm{l}$ PLGANPs. Systematic study of PLGANP kinetics demonstrates that agents entrapped had been released from PLGANPs 70\% after 48 hour treated [22]. To this end, intraperitoneal administrations were initiated 5 days after inoculation, 48 hours earlier than regular therapeutic time [23]. Mice received one therapy every 2 days for a total of 12 treatments and were sacrificed 3 days after the last adminis-

Table 1. Characteristics of two pshDNA/PLGANPs.

\begin{tabular}{lcccc}
\hline & MD $(\mathrm{nm})$ & PDI & EE $(\%)$ & GLR (\%) \\
\hline pshCD44/PLGANPs & $250.98 \pm 13.8$ & $0.20 \pm 0.00$ & $85.91 \pm 2.82$ & $1.72 \pm 0.12$ \\
pshHK/PLGANPs & $226.83 \pm 3.18$ & $0.18 \pm 0.02$ & $89.16 \pm 3.35$ & $1.83 \pm 0.07$ \\
\hline $\begin{array}{l}\text { MD: mean diameters; PDI: polydispersity index; EE: entrapment efficiency; } \\
\text { GLR: gene-loading rate }\end{array}$
\end{tabular}

tration. Intraperitoneal tumors were resected and weighted immediately to evaluate antitumor efficiacy.

Alginate-encapsulated tumor cell assay. An alginate-encapsulated assay was done in vivo to explore suppression of angiogenesis. Briefly, SKOV3 cells were suspended in 1.5\% solution of sodium alginate (Sigma) and added dropwise into a swirling solution of $250 \mathrm{mM} \mathrm{CaCl}_{2}$. Each alginate beads containing $2 \times 10^{5}$ tumor cells per bead were implanted s.c. into an incision made on the dorsal side with four beads per mouse. Six $\mathrm{BALB} / \mathrm{c}$ female nude mice were grouped and treated as described before. Treatment was initiated on the same day of implanting beads. Two weeks later, beads were photographed when exposured surgically.

Histologic analysis. Intraperitoneal tumors were fixed in $4 \%$ paraformaldehyde, embedded in paraffin and cut into 3 $5 \mu \mathrm{m}$ sections. Immersing deparaffinized tumor sections into $10 \mathrm{mM}$ citrate buffer ( $\mathrm{pH}$ 6.0) and heating in an autoclave for 5 minutes in saturated steam for antigen retrieval. Endogenous peroxidase activity was quenched in $3 \% \mathrm{H}_{2} \mathrm{O}_{2}$ for 10 minutes, and nonspecific binding sites of reagents were subsequently blocked with homeotypic nonimmunoglobulin of secondary antibody at $37^{\circ} \mathrm{C}$ for 20 minutes. Then sections were incubated with the primary antibody (Cell Signaling Technology, Boston, MA, USA and Santa Cruz Biotechnology, Santa Cruz, CA), Ki67 (ZSGB-BIO, Beijing, China) and CD31 (ZSGB-BIO, Beijing, China) at $4^{\circ} \mathrm{C}$ overnight. The next day, sections were incubated with streptavidin-biotin-horseradish peroxidase complex for 40 minutes at $37^{\circ} \mathrm{C}$, then incubated with biotinylated secondary antibody at $37^{\circ} \mathrm{C}$ for 40 minutes. Colorimetric detection was performed with diaminobenzidine.

TUNEL assay for cell apoptosis. Apoptotic cells within tumor tissue were evaluated by using a commercially available TUNEL kit (DeadEnd ${ }^{\mathrm{TM}}$ Fluorometric TUNEL System, Promega, Madison, WI), following the manufacturer's protocol. The apoptotic index was assessed by calculating the average percentage of green fluorescence-positive cells in 10 random fields from at least 3 seconds for each group at $\times 400$ magnification.

Toxicity evaluation. The possible adverse effects and toxicity of therapy, such as weight loss, ruffling of fur, skin ulceration, appetite and behavior changes, and cachexia were observed and evaluated. Tissues of heart, liver, spleen, lung and kidney were stained with hematoxylin and eosin (H\&E) staining and evaluated by independent pathologists.

Statistical analysis. Student's test for two-group comparison and one-way ANOVA for multiple-group comparisons were performed to analyze all statistical analysis. A $P$ value below 0.05 was defined as statistically significant. The Statistical Package for the Social Sciences 13.0 (SPSS, Inc., Chicago, IL) was used for all statistical analyses.

\section{Results}

Characterization of pshCD44/PLGANPs. MD, PDI, EE and GLR of two pshDNA/PLGANPs (pshCD44/PLGANPs and pshHK/PLGANPs) were showed in table 1. Higher EE 

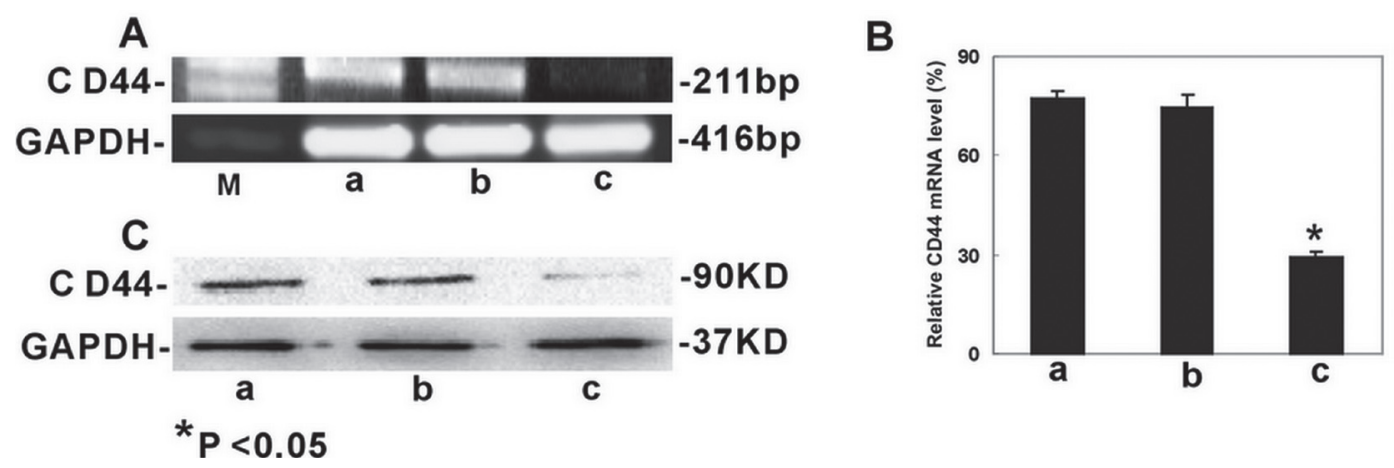

Figure 1. Down-regulation of CD44 expression using shRNA loaded in PLGANPs in vitro and in vivo. (A) and (B), RT-PCR on cDNA obtained from SKOV-3 cells treated with shRNA nanoparticles against CD44. (C), Western Blot on protein abstract obtained from SKOV-3 cells treated with shRNA nanoparticles against CD44. The housekeeper gene GAPDH used as internal control. M means marker used in RT-PCR. a, untreated (0.9\% sodium chloride) group; b, empty-vector (pshHK/PLGANPs) group; c, pshCD44/PLGANPs group. Data were expressed as means \pm SD. ${ }^{\star} P<0.05$ versus the two control groups, respectively.

and GLR were showed in our study than previous studies [19, $22,24]$. Ultracentrifugation was used to remove the free drugs and polyvinyl alcohol (PVA) in the supernatant as described previously [24].

Down-regulation of CD44 expression in vitro. To evaluate the expression of CD44 after treatment with the pshCD44/PLGANP in vitro, SKOV3 cells were collected at 60-72 hours after transfections and analyzed by RT-PCR and western blot.

Semi-quantitative RT-PCR indicated that expression of CD44 in pshCD44/PLGANPs group was suppressed by $61 \%$ and $62 \%$ compared with that in pshHK/PLGANPs and untreated group $(P s<0.001)$ (Fig. $1 \mathrm{~A}, \mathrm{~B})$. There was no significant difference between two control groups. The density of RT-PCR bands was measured by Quantity One and normalized with GAPDH (Fig. 1 A).

Suppression of CD44 at the protein level was observed in SKOV3 after treatment with pshCD44/PLGANPs in vitro (Fig. 1 C). Owing to random lack of 1-10 variant exons in transcription level and complicated modifications in translation level, CD44 protein appears as a wide range of varying molecular weights $(80-250 \mathrm{kDa})$ due to the presence of multiple glycoforms [25]. But to CD44 proteins reactive to the antibody used in this work, the molecular weight is about $90 \mathrm{kDa}$. Obviously decreased expression of CD44 in pshCD44/PLGANPs group compared with that in the control groups (Fig. 1 C). This result was consistent with that of RT-PCR. To this end, these findings demonstrated that CD44 expression could be down-regulated effectively in mRNA and protein levels in vitro by pshCD44/PLGANPs.

pshCD44/PLGANPs inhibited tumor xenografts growth in nude mice. To further assess the effectiveness of CD44 gene suppression in vivo, intraperitoneal tumors model were established to evaluated inhibition of CD44 in tumor growth. Tumor baring mice were treated with pshCD44/PLGANPs, pshHK/PLGANPs or $0.9 \% \mathrm{NaCl}$ every 3 days as detailed in the materials and methods. The mice were sacrificed 3 days after the final nanoparticles injection. All tumors were collected and photographed.

In all mice, tumor nodules were scattered around the pelvis. These lesions varied in size, but were larger and more numerous in the two control groups (Fig. $2 \mathrm{~A}, \mathrm{~B}$ ). The average weight was $1.46 \pm 0.28 \mathrm{~g}, 1.32 \pm 0.14 \mathrm{~g}$ and $0.73 \pm 0.18 \mathrm{~g}$ in the untreated, pshHK/PLGANPs and pshCD44/PLGANPs groups, respectively. Tumor weight in pshCD44/PLGANPs group was reduced by $45 \%$ and $50 \%$ compared with in pshHK/PLGANPs and $0.9 \% \mathrm{NaCl}$ groups, respectively $(P s<$ 0.001 ) (Fig. 2 C). There are no significant differences between two control groups $(P>0.05)$.

Suppressions of CD44 genes in vivo. Tumors from each group were used for RT-PCR and western blot analyses. The level of CD44 mRNA suppressed in pshCD44/PLGANPs group by $68 \%$ and $69 \%$ when compared to pshHK/PLGANPs and $0.9 \% \mathrm{NaCl}$ groups (Fig. $3 \mathrm{~A}, \mathrm{~B})(P s<0.001)$, respectively. Western Blot confirm above results in protein level (Fig. $3 \mathrm{C}$ ). In addition, immunochemical staining of CD44 in tumor tissues further demonstrated the suppression of CD44 in the tumors of pshCD44/PLGANPs treated mice (Fig.3 D).

Efficacies of cell proliferation, apoptosis and angiogenesis by pshCD44/PLGANPs in vivo. To explore the mechanism of tumor suppression elicited by the pshCD44/ PLGANPs in vivo, we measured their effects on several biological end points, including cell proliferation (Ki-67), apoptosis (TUNEL), and antiangiogenesis.

Cell proliferation in tumor tissues was evaluated by Ki-67 staining. Minimal reduction of Ki-67 expression was observed in pshCD44/PLGANPs $(27.5 \% \pm 3.7 \%)$ group compared with that in pshHK/PLGANPs $(44.7 \% \pm 5.3 \%)$ or untreated group $(49.4 \% \pm 5.4 \%)$, respectively (Ps < 0.001) (Fig. 4 A).

An imbalance of cell proliferation with apoptosis can contribute to tumor growth and invasion. We therefore also performed TUNEL staining to assay for apoptotic cells in 
A

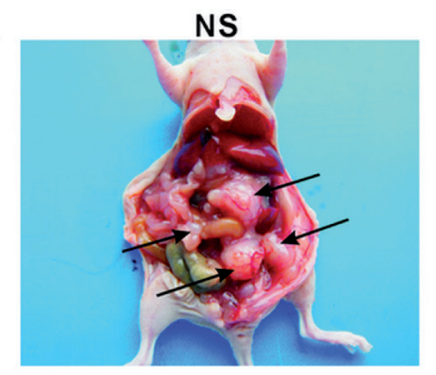

B

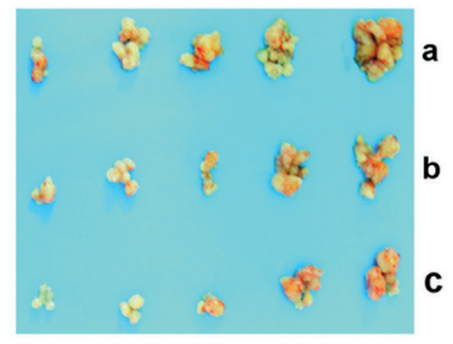

${ }^{*} \mathrm{P}<0.05$
pshHK/PLGANPs
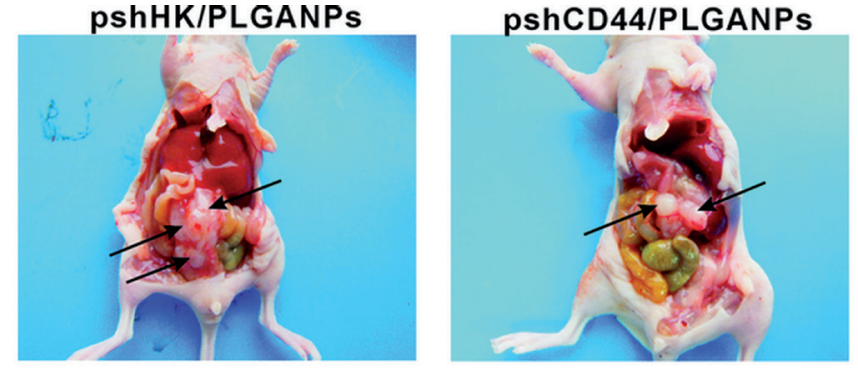

C

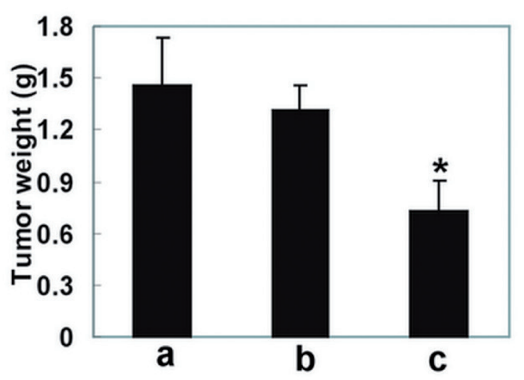

Figure 2. Silencing CD44 inhibits intraperitoneal tumor xenografts growth in nude mice. (A) Intraperitoneal tumor nodules, of various sizes, were scattered in the pelvic and abdomen from each group. (B) All tumors were collected carefully and weighed immediately. a, untreated ( $0.9 \%$ sodium chloride) group; $b$, emptyvector (pshHK/PLGANPs) group; c, pshCD44/PLGANPs group. (C) Intraperitoneal tumor weight. Values are mean \pm SD. ${ }^{*} P<0.001$ versus control groups.

A

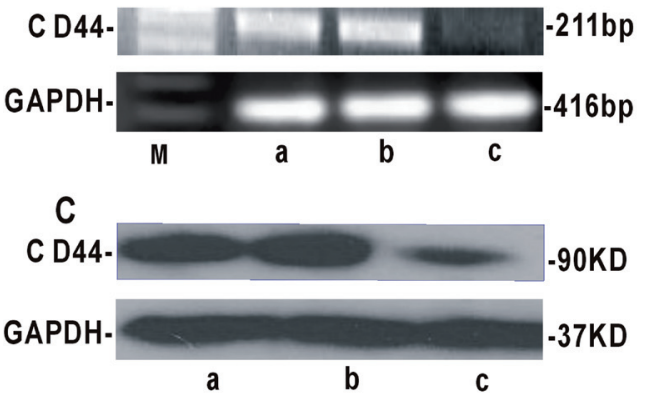

B

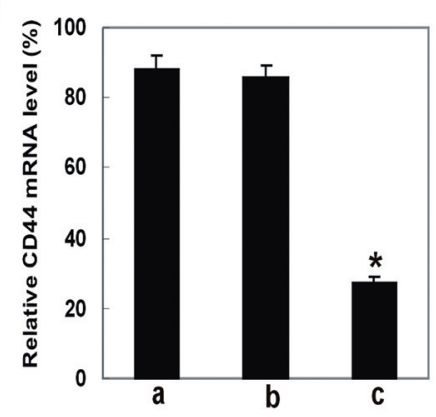

D
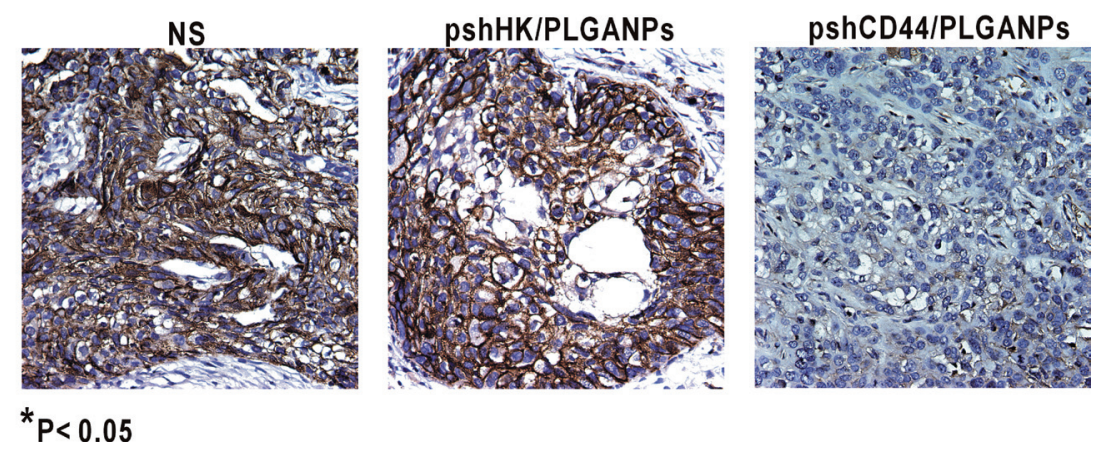

Figure 3. Down-regulation of CD44 expression using shRNA loaded PLGANPs in vivo. (A) and (B), RT-PCR on cDNA obtained from tumors treated with shRNA nanoparticles against CD44. (C) Western Blot on protein abstract obtained from tumors treated with shRNA nanoparticles against CD44. (D) Immunostaining of CD44 in tumor tissue. Original magnification, $\times 400$. The housekeeper gene GAPDH used as internal control. M means marker used in RT-PCR. a, untreated $(0.9 \% \mathrm{NaCl})$ group; b, empty-vector (pshHK/PLGANPs) group; c, pshCD44/PLGANPs group. Data were expressed as means \pm SD. ${ }^{\star} P<0.05$ versus the two control groups, respectively. 

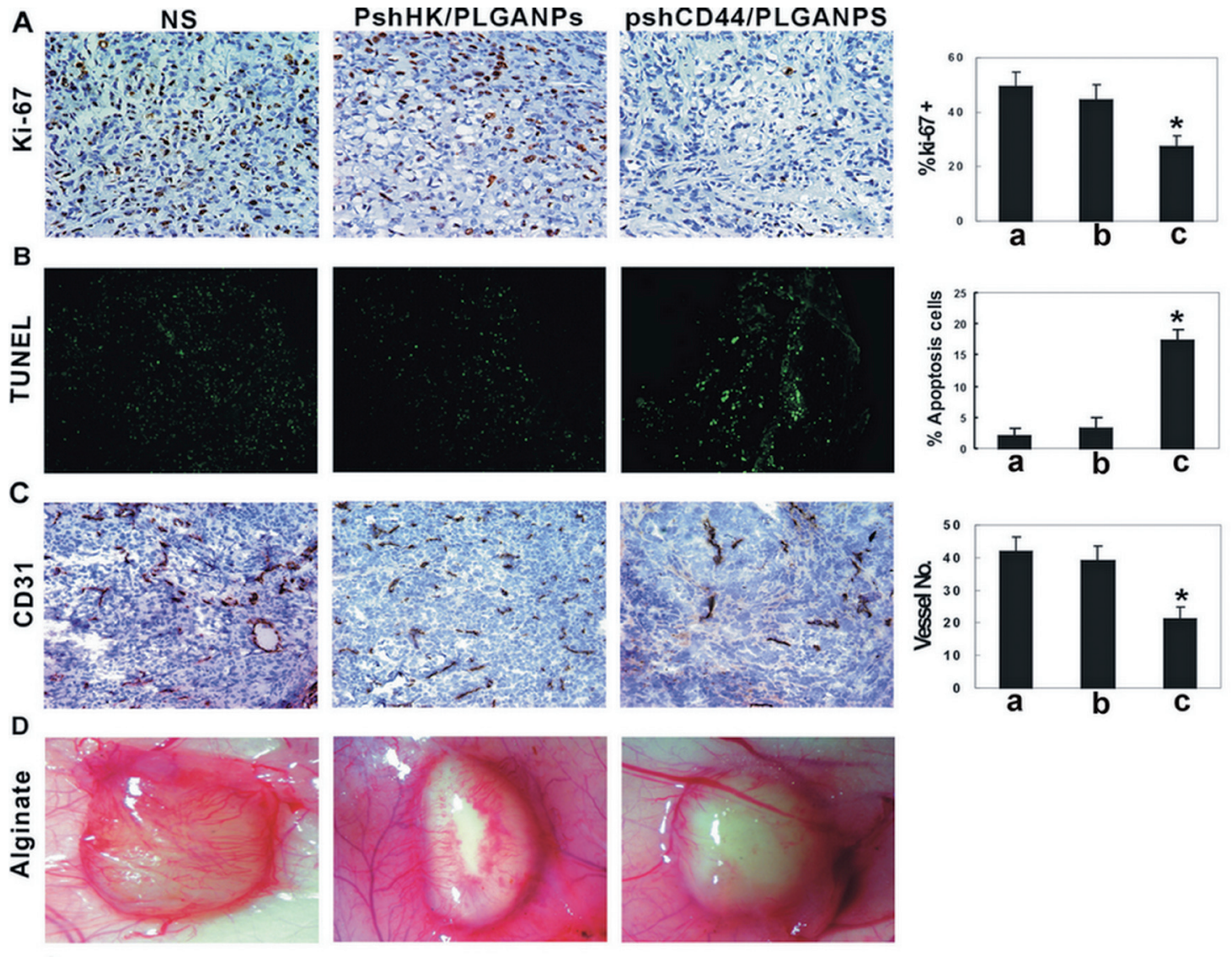

${ }^{*} \mathrm{P}<0.05$

Figure 4. Effects of pshCD44/PLGANPs on cell proliferation, apoptosis and angiogenesis in vivo. (A) The percentage of positive Ki-67 in each group. (B) The positive TUNEL nuclei in each group. (C) Representative images of immunohistochemical CD31 staining. MVD was determined after immunohistochemical staining for CD31 staining in each group. (D) Vascularization of alginate beads from each group. a, untreated group (0.9\% sodium chloride); b, empty-vector (pshHK/PLGANPs) group; c, pshCD44/PLGANPs group. The results are presented as mean \pm SD $(n=5) .{ }^{*} P<0.005$ versus two control groups.

tumor tissues. A significant increase of apoptosis in pshCD44/ PLGANPs group $(16.5 \% \pm 3.5 \%)$ compared with either pshHK/ PLGANPs $(3.3 \% \pm 1.6 \%)$ or untreated group $(2.1 \% \pm 1.2 \%)$, respectively $(P s<0.001)$ (Fig. 4 B).

Angiogenesis is important in tumorigenesis, so antiangiogenic therapies are important in the treatment of cancer. Although literature seldom demonstrates clear functions of CD44 in angiogenesis, there must be some roles of CD44 involved in. Because CD44 acts as an important adhesive factor on the surface of vascular endothelial cells, we therefore sought to evaluate the effects of suppressing CD44 protein on angiongenesis in vivo. To do so, we measured microvessel density (MVD) in endothelial cells of tumor sections by staining for the vascular marker CD31. In addition, we performed an alginate encapsulation test to evaluate vessel formation in vivo. The mean MVD was significantly decreased in tumors treated with the pshCD44/PLGANPs (MVD: $21 \pm 3.6$ ) compared with pshHK/PLGANP (MVD:
$39 \pm 4.5)$ and untreated group (MVD: $42 \pm 4.4$ ), respectively $(P s<0.001)$ (Fig. 4 C). Furthermore, the inhibition of angiogenesis was evaluated by alginate encapsulation test. The alginate implants showed a significant reduction in the number of new vessels in the pshCD44/PLGANPs group, compare to the control groups. It is consistent with results of CD31 staining.

Toxicity observation. No gross abnormality was observed in treated mice of each group. Furthermore, H\&E histological evaluation of the liver, lung, kidney, spleen, brain, heart, pancreas, intestine and bone marrow by two pathologists did not reveal any significant differences between treatment groups and control groups (data not show).

\section{Discussion}

By regulating the expressions of genes involved in tumorigenesis, gene therapy offers a unique method to change 
the tumor and its microenvironment. shRNA has been successfully therapeutically used in many anti-cancer studies, including the treatment of ovarian cancer and was choosen in this study for its characteristics of easy preparation, relative stability and sustained expression compared to siRNA[26, $27,28]$. CD44 belongs to a large family of proteins that play an important role in cell-cell and cell-matrix adhesion and is expressed in various cells [29]. As being the primary receptor for hyaluronic acid (HA), CD44 plays an essential role in cell adhesion and cell migration [30]. CD44 is overexpressed in ovarian cancer and proved to be one marker of ovrian cancer stem cells [31]. These characteristics make CD44 to be an ideal target for shRNA gene therapy. Studies put insight to silencing CD44 gene in suppression growths of different tumors, including colon cancer, nasopharyngeal cancer and ovarian cancer $[7,8,10]$. But the transient suppression of tumor growth was shown as using siRNA targeting CD44 gene in ovarian cancer [10]. In this study, we demonstrate that silencing of CD44 with shRNA, expression stable and sustained more than siRNA, significantly inhibit the growth of human ovarian cancer xenografts in nude mice compared with controls, similar to previously reported results [10]. Other unknown functions of silencing CD44, including influence of cell proliferation, cell apoptosis and antiangiogenesis, were explored in tumor progression and metastasis.

An effective and safe delivery system is essential for the application of gene therapy. Although many viral vectors demonstrate high transduction efficacy, toxicity continues to be a concern during clinical application [30]. Over the last decade, studies were done and improvements in non-viral vectors made some excellent non-viral vectors stand out, which were proved to owe some advantages than viral vectors [13-15]. PLGA is a relatively new carrier system being employed to deliver nutrition to malignant tumors [24, 31]. As a non-viral vector, PLGA is attractive for plenty of virtues. Firstly, PLGA nanoparticles exhibit excellent biocompatibility and low cytotoxicity in vivo. Secondly, PLGA nanoparticles are slowly released in vivo, which may increase the half-life and efficacy of the drugs or genes being delivered. Finally, PLGA are harmlessly biodegraded into $\mathrm{CO}_{2}$ and $\mathrm{H}_{2} \mathrm{O}$ after exerting their functions in vivo $[16,18,22]$. We previously demonstrated that, PLGANPs can be used to deliver genes into tumor cells $[20,32]$. In the present study, PLGANPs were used to deliver the recombinant shRNA plasmid targeting CD44 gene in SKOV-3 derived tumors of nude mice. As a result, the expression of CD44 was lessened in the tumors treated with pshCD44/PLGANPs compared with the control tumors, indicated by RT-PCR, western blot and immunohistochemisty analysis. The biologic features of PLGA have been studied extensively. Knocking down CD44 expression suppressed tumor growth in vivo, indicating that PLGANPs could deliver a large component plasmid into tumor cells successfully. No toxicity was observed in this study, suggesting that the PLGANPs should be safe in gene therapy. However, further toxicity assessment should be performed.
To elucidate the antitumor mechanism of CD44 in vivo, several biologic points of tumorigenesis were explored including cell proliferation, cell apoptosis and antiangiogenesis. Data from Ki67 staining and TUNEL assay suggested that silencing CD44 caused in significant reduction of cell proliferation and increase of cell apoptosis compared with control groups. Cells treated with siRNA against CD44 exhibit increased apoptosis compared with control siRNA [10]. Antitumor efficacy of CD44 silencing therapy was bases on disassembling interaction of CD44 and hyaluronidase therefore increasing of apoptosis [30]. Using shRNA, we knocked down CD44 expression and reconfirmed those results in above studies. Angiogenesis was assessed by CD31 staining and alginate encapsulation test. A significant reduction in new vessels was observed in tumors receiving pshCD44/PLGANPs treatment, which could be one of major mechanisms in inhibition of tumor growth, but the role of CD44 is less clearly revealed. Antiangiogenesis is a complex procedure and contains of multiple steps in procedures. It is likely that induction of apoptosis in endothelial cells may be one mechanism by which CD44 knockdown can influence tumor angiogenesis. It is consistent with the result of one report that cells treated with siRNA against CD44 exhibit increased apoptosis compared with control siRNA [10]. CD44 is involved in the adhesion of endothelial cells to the vascular matrix, potentially explaining why we observed less vascularization in the pshCD44/PLGANPs treated tumors. This is consistent with a prior report that described how the multimeric signaling complex of CD44 and it's related receptor tyrosine kinases are involved in angiogenesis [33]. In addition, preventing the binding of hyaluronidase to CD44 increases apoptosis [31]. However, the actual role of CD44 in angiogenesis is unclear and further study is needed to address this question. All above results indicated that antitumor effect maybe in part due to influence of antiangiogenesis, decrease of proliferation, and induction of apoptosis by knocking down of CD44.

Acknowledgments: This work was kindly supported by grants from 2009ZX09503-020, 2010CB529905, 81372246 and 20120181110029.

\section{References}

[1] JERMAL A, SIEGEL R, XU J, WARD E. Cancer statistics, 2010. CA Cancer J Clin 2010; 60: 277-300. http://dx.doi. org/10.3322/caac.20073

[2] PONTA H, SHERMAN L, HERRLICH PA. CD44: from adhesion molecules to signaling regulators. Nat Rev Mol Cell Biol 2003; 4: 33-45. http://dx.doi.org/10.1038/nrm1004

[3] LESSAN K, AGUIAR DJ, OEGEMA T, SIEBENSON L, SKUBITZ APN. CD44 and $\beta 1$ integrin mediate ovarian carcinoma cell adhesion to peritoneal mesothelial cells. Am J Pathol 1999; 154: 1525-1537. http://dx.doi.org/10.1016/S00029440(10)65406-5 
[4] MISRA S, HASCALL VC, DE GIOVANNI C, MARKWALD RR, GHATAK S. Delivery of CD44 shRNA/nanoparticles within cancer cells: perturbation of hyaluronan/CD44v6 interactions and reduction in adenoma growth in Apc Min/+MICE. J Biol Chem 2009; 18: 12342-12446.

[5] GUNTHERT U, HOFMANN M, RUDY W, REBER S, ZOLLER M, HUASSMANN I et al. A new variant of glycoprotein CD44 confers metastatic potential to rat carcinoma cells. Cell 1991; 65: 13-24. http://dx.doi.org/10.1016/00928674(91)90403-L

[6] DRAFFIN JE, MCFARLANE S, HILL A, JOHNSTON PG, WAUGH DJJ. CD44 potentiates the adherence of metastatic prostate and breast cancer cells to bone marrow endothelial cells. Cancer Res 2004; 64: 5701-5711. http://dx.doi. org/10.1158/0008-5472.CAN-04-0389

[7] SUBRAMANIAM V, VINCENT IR, GILAKJAN M, JOTHY S. Suppression of human colon cancer tumors in nude mice by siRNA CD44 gene therapy. Exp Mol Pathol 2007; 83: 332-340. http://dx.doi.org/10.1016/j.yexmp.2007.08.013

[8] SHI Y, TIAN Y, ZHOU YQ, JU JY, QU L et al. Inhibition of malignant activities of nasopharyngeal carcinoma cells with high expression of CD44 by siRNA. Oncol Report 2007; 18: 397-403.

[9] BAPAT SA, MALI AM, KOPPIKAR CB, KURREY NK. Stem and progenitor-like cells contribute to the aggressive behavior of human epithelial ovarian cancer. Cancer Res 2005; 65: 3025-3029.

[10] LI CZ, LIU B, WEN ZQ, WANG CX, LI HY. Inhibition of CD44 expression by small interfering RNA to suppress the growth and metastasis of ovarian cancer cells in vitro and in vivo. Folia Biologica (Praha) 2008; 54: 180-186.

[11] PAUL CP, GOOD PD, WINER I, ENGELKE DR. Effective expression of small interfering RNA in human cells. Nat Biotechnol 2002; 20: 505-508. http://dx.doi.org/10.1038/ nbt0502-505

[12] RAPER SE, CHIRMULE N, LEE FS, WIVEL NA, BAGG A et al. Fatal systemic inflammatory response syndrome in a ornithine transcarbamylase deficient patient following adenoviral gene transfer. Mol Genet Metab 2003; 80: 148-158. http://dx.doi.org/10.1016/j.ymgme.2003.08.016

[13] YOUNG LS, MAUTNER V. The promise and potential hazards of adenovirus gene therapy. Gut 2001; 48: 733-736. http://dx.doi.org/10.1136/gut.48.5.733

[14] GAO Y, XU Z, CHEN S, GU W, CHEN L, LI Y. Arginine-chitosan/DNA self-assemble nanoparticles for gene delivery: in vitro characteristics and transfection efficiency. Int J Pharm 2008; 359: 241-246. http://dx.doi.org/10.1016/ j.ijpharm.2008.03.037

[15] SUZUKI R, NAMAI E, ODA Y, NISHIIE N, OTAKE $S$ et al. Cancer gene therapy by IL-12 gene delivery using liposomal bubbles and tumoral ultrasound exposure. J Control Release 2010; 142: 245-250. http://dx.doi.org/ 10.1016/j.jconrel.2009.10.027

[16] FONSECA C, SIMOES S, GASPAR R. Paclitaxel-loaded PLGA nanoparticles, preparation, physicochemical characterization and in vitro anti-tumoral activity. J Control Release 2002; 83: 273-286. http://dx.doi.org/10.1016/S0168-3659(02)00212-2
[17] BENNY O, DUVSHANI-ESHET M, CARGIOLI T, BELLO L, BIKFALVI A et al. Continuous delivery of endogenous inhibitors from poly(lactic-co-glycolic acid) polymeric microspheres inhibits glioma tumor growth. Clin Cancer Res 2005; 11: 768-776.

[18] PEREZ C, SANCHEZ A, PUTNAM D, TING D, LANGER $\mathrm{R}$ et al. Poly (lactic acid)-poly (ethylene glycol) nanoparticles as new carriers for the delivery of plasmid DNA. J Control Release 2001; 75: 211-224. http://dx.doi.org/10.1016/S01683659(01)00397-2

[19] CUI FY, SONG XR, LI ZY, LI SZ MU B et al. The pigment epithelial-derived factor gene loaded in PLGA nanoparticles for therapy of colon carcinoma. Oncol Rep 2010; 24: 661-668.

[20] SUN C, YI T, SONG X, LI S, QI X et al: Efficient inhibition of ovarian cancer by short hairpin RNA targeting claudin-3. Oncol Rep 2011; 26: 193-200.

[21] ROSCIC-MRKIC B, FISCHER M, LEEMANN C, MANRIQUE A, GORDON CJ et al. RANTES (CCL5) uses the proteoglycan $\mathrm{CD} 44$ as an auxiliary receptor to mediate cellular activation signals and HIV-1 enhancement. Blood 2003; 102: 1169-1177. http://dx.doi.org/10.1182/blood2003-02-0488

[22] SONG XR, ZHAO Y, WU WB, BI Y, CAI Z et al. PLGA nonoparticles simultaneously loaded with vincristine sulfate and verapamil hydrochloride: systematic study of particle size and drug entrapment efficiency. Int J Pharmaceut 2008; 350: 320-329. http://dx.doi.org/10.1016/j.jpharm.2007.08.034

[23] LIN XJ, CHEN XC, WEI YQ, ZHAO J, FAN L et al. Efficient inhibition of intraperitoneal human ovarian cancer growth and prolonged survival by gene transfer of vesicular stomatitis virus matrix protein in nude mice. Gynecol Oncol 2007; 104: 540-546. http://dx.doi.org/10.1016/j.ygyno.2006.09.022

[24] SONG XR, CAI Z, ZHENG Y, HE G, CUI FY et al. Reversion of multidrug resistance by co-encapsulation of vincristine and verapamil in PLGA nanoparticles. Eur J Pharm Sci 2009; 37: 300-305. http://dx.doi.org/10.1016/j.ejps.2009.02.018

[25] BROWN TA, BOUCHARD T, JOHN TS, WAYNER E, CARTER WG. Human keratinocytes express a new CD44 core protein $(\mathrm{CD} 44 \mathrm{E})$ as a heparan-sulfate intrinsic membrane proteoglycan with additional exons. J Cell Biol 1991; 113: 207-221. http://dx.doi.org/10.1083/jcb.113.1.207

[26] HANNON GJ, ROSSI JJ. Unlocking the potential of the human genome with RNA interference. Nature 2004; 431: 371-378. http://dx.doi.org/10.1038/nature02870

[27] BAI Y, DENG H, YANG Y, ZHAO X, WEI Y et al. VEGFtargeted short hairpin RNA inhibits intraperitoneal ovarian cancer growth in nude mice. Oncology 2009; 77: 385-394. http://dx.doi.org/10.1159/000279385

[28] SU D, DENG H, ZHAO X, ZHANG X, CHEN L et al. Targeting CD24 for treatment of ovarian cancer by short hairpin RNA. Cytotherapy 2009; 11: 642-652. http://dx.doi.org/10.1080/ 14653240902878308

[29] SKUBITZ, AP. Adhesion molecules. Cancer Treat Res 2002; 107: 305-329.

[30] GUO Y, GUO H, ZHANG L, XIE H, ZHAO X et al. Genomic analysis of anti-Hepatitis B Virus (HBV) activity by small interfering RNA and lamivudine in stable HBV-producing 
cells. J Virol 2005; 79: 14392-14403. http://dx.doi.org/10.1128/ JVI.79.22.14392-14403.2005

[31] AL-HAJJ M, WICHA MS, BENITO-HERNANDEZ A, MORRISON SJ, CLARKE MF. Prospective identification of tumorigenic breast cancer cells. Proc Natl Acad Sci U S A 2003; 100: 3983-3988. http://dx.doi.org/10.1073/ pnas. 0530291100

[31] KANG BK, CHON SK, KIM SH, JEONG SY, KIM MS et al. Controlled release of paclitaxel from microemulsion contain- ing PLGA and evaluation of anti-tumor activity in vitro and in vivo. Int J Pharmaceut 2004; 286: 147-156. http://dx.doi. org/10.1016/j.ijpharm.2004.08.008

[32] QIX, SONG X, LIU P, YI T, LI S et al. Antitumor effects of PLGA nanoparticles encapsulating the human PNAS-4 gene combined with cisplatin in ovarian cancer. Oncol Rep 2011; 26: 703-710.

[33] LESLEY J, HYMAN R, KINCADE PW. CD44 and its interaction with extracellular matrix. Adv Immunol 1993; 54: 271-335. http://dx.doi.org/10.1016/S0065-2776(08)60537-4 